\title{
Reflections on the Role of Technology in City- wide Collaborative Learning
}

\author{
$\underline{\text { doi:10.3991/ijim.v3i2.746 }}$ \\ I. Canova Calori and M. Divitini \\ Department of Computer and Information Science, Trondheim, Norway
}

\begin{abstract}
In this paper we investigate collaborative learning that takes place in a city with the support of mobile and wireless technology. Based on a literature review, we identify and discuss four main roles that technology can play in supporting (1) performance of shared tasks, (2) social networking, (3) active participation, and (4) visibility of learning. We claim that the full potential of new technology emerges by supporting learning that comes from exploration, interaction, and serendipity. Realizing this potential raises a number of technical challenges that are still largely unexplored. In particular, we claim that there is a need to move from applications design to a serviceoriented infrastructure that eases the development and adaptation of applications for multiple and interleaved learning experiences. Services that are common across different learning scenarios and can be used as building blocks need to be identified. The aforementioned roles are the first step towards this direction.
\end{abstract}

Index Terms-City-wide learning, collaborative learning, learning scenarios, technology mediated learning.

\section{INTRODUCTION}

The advances and diffusion of mobile and ubiquitous technology have influenced considerably our everyday life (the way we communicate, arrange our activities, etc.), changing our habits and practices by freeing us from the confines of the desktop activities [1]. Ubiquitous and mobile technologies have also affected the younger generations that have grown up being familiar with those systems and being used to handle them. For example, a study conducted by Jones, Fleuriot, Williams, \& Wood [2] proved that children are attracted by the use and potential of pervasive computing and mobile technology; this means that children opportunities to engage with the urban environment are increased. In general, there has been a growing interest in physical spaces and on the role of technology in city-wide environments $[1,3,4,5,6,7,8$, 9]. Many projects investigating new kind of learning activities have also moved their attention to the urban environment [2, 10, 11, 12, 13, 14]. Ubiquitous and mobile technologies might facilitate learners to continue their learning outside their classrooms, when and where they desire, through exploration and interaction. Learning activities will not be confined simply to formal learning in the classroom, but more activities will be carried out outside it, e.g. in museums, libraries.

This research is conducted in the framework of the FABULA project (www.idi.ntnu.no/ divitini/FABULA/), which aims at developing novel principles and technical solutions for city-wide learning enabled by seamless roaming in mobile networks, with focus on services that allow people to take an active role in collaborative processes of knowledge construction and sharing.

In this paper we investigate how technology can support different aspects of mobile and collaborative learning in a city-wide context. The research area we want to address in this paper is at the intersection between citywide application research and collaborative and mobile learning (Fig. 1). That is, our focus is not simply on the role of mobile technology, but all kind of technology that can support learning that occurs across urban locations, learning arenas and communities.

We believe that these applications open up for a new space of possibilities that is still largely unexplored, challenging many of our assumptions on learning experience and communities.

City-wide technologies allow supporting not only small groups of students performing specific tasks, but also the collaboration that takes place within loosely coupled groups. Considering the mobility of students, we believe that support for learning cannot neglect issues connected to participation to multiple communities, and how mobility across communities can hinder or foster learning. This choice finds a clear grounding in theoretical backgrounds that look at learning as situated and, as such, relates to learning as participation in communities [15]. While the Internet has put the focus on distance education and on collaboration among people that are geographically distributed, mobile and wireless services allow to bring again into the picture local issues, recognizing the critical role of place and local communities in learning, supporting not only interactions with "others around the world, but also -and, perhaps more importantly, with people nearby. Groups of people using these tools will gain new forms of social power, new ways to organize their interactions and exchanges just in time and just in place” [16] pp. xii. The challenge is therefore to design what Thackara [17] calls new geographies of learning, "configurations of space, place, and network that respect the social and collaborative nature of learning - while still exploiting the dynamic potential of networked collaboration” [17] pp. 147.

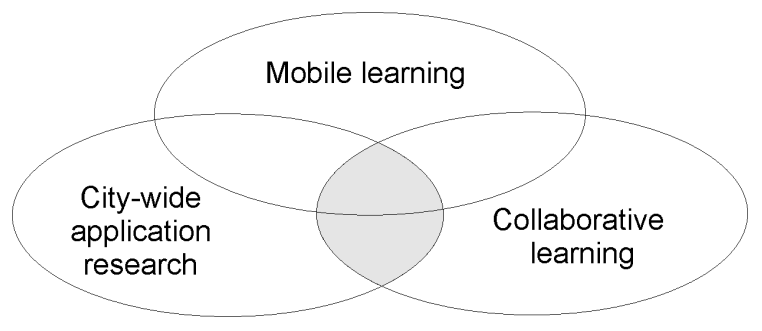

Figure 1. Area of research 
In this paper we reflect on the different roles that technology can play in city-wide collaborative learning. Focusing on a socio-constructivist approach to learning, we have identified in the literature four main roles played by applications in supporting (1) performance of shared tasks, (2) social matching and networking, (3) active participation, and (4) visibility of learning. We underline that the distinction that we provide is mainly for analytical purposes and the different roles are often played in an interleaved way in any given system. The four main roles presented in this paper might not be exhaustive; for instance, we have mainly focused on co-located peer collaboration rather than remote virtual collaboration.

After presenting the different roles, we discuss challenges in the design of support for city-wide learning. In particular, considering the dynamic and the emerging nature of the learning experiences that we aim at supporting, we claim the need to design learning systems that are not monolithic entities, but are rather a dynamic and contextualized composition of services satisfying specific needs. In this perspective one of the challenges ahead is to look at commonalities among different learning contexts to identify basic services that can then be combined, possibly by end-users, to provide more complex support. An initial list of these services includes management of social networks and shared places, as well as support for contextualization of learning.

\section{Roles OF CitY-WIDE APPLiCATIONS IN SUPPORTING COLLABORATIVE LEARNING}

In this section, we present the four main roles that citywide applications play in supporting collaborative learning experiences. In particular, we look at scenarios where learning is mainly promoted through exploration, interaction and serendipity. For instance, we look at applications employed in museums or during field trips that allow students to experience things at hand, exploring both the surroundings and people there, interacting with more experienced peer or experts in the field that they might serendipitously meet there. These scenarios address both formal and informal learning situations where the learning goals might not always be identified a priori. As noted in [18], "for mobile and informal learning, [...] learning objectives may develop on-the-fly as a response to interactions with the environment". In such situations it becomes challenging also to evaluate the learning process, especially when it occurs across multiple settings and technologies, in this case the Vavoula and Sharples [18] suggested to collect evidences that productive learning has happened, e.g. "to watch for instances where learners show responsibility for and initiate their own learning, share learning with experts and peers” [18] pp. 297.

In the following each one of the roles identified is illustrated with a scenario and a brief literature review of relevant systems.

\section{A. Performing Shared Tasks}

This first scenario looks at the city as an arena for performing collaborative learning tasks. Its purpose is to highlight the possibilities of performing shared tasks among a group of people that are distributed. A possible scenario is explained in Table I. There are a number of systems and research efforts that promote and support performance of shared tasks.
Pinkwart, Hoppe, Milrad, \& Perez [19] described the realization of a few scenarios for cooperative use of Personal Digital Assistants (PDAs). They also outlined the possibilities for applications to support collaboration between students in the classroom and other engaged in activities outdoors, allowing them to exchange their ideas and hypotheses peer-to-peer through a mobile application. The students can also project their finding onto an electronic whiteboard to initiate a classroom discussion giving visibility to learning activities to a broader public. This allows another aspect of collaborative learning in the city (i.e. visibility of learning) that will be discussed later in this section.

In [20], the authors presented a shared mixed reality system that support collaborative museum visits. The system supports 3 types of visitor: a physical visitor of the museum that uses a PDA, a virtual reality visitor of the 3D representation of the gallery, and a web visitor that has available a 2D map and mixed reality exhibit objects. The authors showed how shared spatial location can intuitively support collaboration. The authors also claimed that this kind of systems can be employed in many other situations and contexts where "collaboration takes place around objects”, for instance in other kind of field trips or learning experiences.

In [21], the mediaBoard system, to encourage learners to contribute to online projects, is presented. This system was designed for supporting communication and the exchange of ideas among students using text and picture sent using either mobile phones or PC. Cook, Bradley, Holley, Smith, \& Haynes [22] presented a learning environment that facilitates teamwork over multiple communication devices making use of a mediaBoard system as a multimedia message board. Students used the mediaBoard to communicate with their team and collaborate together to complete their assignment.

TABLE I.

SCENARIO 1 - PERFORMING SHARED TASKS

The teacher has just given out a
new assignment about pollution.
The students have to investigate
the status of their local
environment (exploration).
Anna, George, and Isabel are
assigned to the same group and
they decide to divide their tasks.
Anna will go out and collect
data in the main street, George
will cover the area around the
main square, while Isabel will
monitor the status of the river.
While Isabel is at the river, she meets an old fisherman who has a lot
of information on how pollution has impacted during the years the
life in the river (serendipity). She uses her PDA to contact the others
and ask if they have some questions they would like to ask.
In the meanwhile, Anna sends to George the data she has collected
to check if the process she is following is correct (interaction among
group members).
While out in the field, George meets a class working on a similar
project. He shows the data he has collected so far to one of the
students. The teacher of the class overhears the conversation and
joins in, giving some good tips about their approach (serendipity and
interaction). George is now able to answer Anna in a more precise
way.


Several other projects have addressed the issue of supporting performance of shared tasks in the form of collaborative games. Kurti, Spikol, Milrad, Svensson, \& Pettersson [23] proposed a game-base activity that fostered children's collaborative problem solving skills within a group of students across different locations (indoor in a museum and two others outdoors location). Several smart phones, in addition to desktop computers, were used for several purposes: to support communication with instant messaging applications, to trigger events through a code reader, to control the contents related to a specific task, etc. Activity Theory was used to guide the design process; the activities were designed in order to impose the division of labor that successfully forced the coordination of tasks and collaboration among subgroups.

Savannah is another important project that promotes collaborative learning through a strategy-based adventure game where a virtual space, the savannah, is mapped directly onto a real space. The children act as they were lions in a savannah, navigating through the environments by using mobile handheld devices. Using aspects of game play, Savannah challenges children to explore and survive in the augmented space. In order to succeed they must coordinate their efforts adopting the strategies used by lions [24]. The development of collaborative strategies in games has been observed also in other city-based games, like in the CityTag project [25].

\section{B. Social Matching and Social Networking}

With this scenario we want to highlight the possibility to enhance the social aspects of collaborative learning in the city environment mainly in two ways: by strengthening the feeling of connectedness among friends and by promoting interaction with strangers based on affinity. See Table II for an example.

TABLE II.

SCENARIO 2 - SOCIAL MATCHING AND SOCIAL NETWORKING

Back to school Anna updates her
profile on the mobile by setting
'pollution' among her interests. A
few minutes later, the affinity
system of the school notifies her
about someone else in her vicinity
that has similar interests
(serendipity). Anna decides to send
a message to this peer and invite
him/her to meet. The other peer
accepts, it is Cristine, a student that
Anna does not know so well. They
sit together at a table and they
discuss about their common
interests. Cristing
its local impact. Anna thinks that she could integrate Cristine's
information on the assignment she has to write, while some of the
information that Anna collected during her visit could be useful for
Cristine as well. They exchange their contacts and agree in sharing
their information (serendipity and interaction).
Eventually, Anna starts writing her assignment, so she sets the status
of her mobile to "busy working". Then, she checks the status of her
friends and she finds out that also George has set the same status. He
is probably working on their assignment as well. She sends him a
message that will hopefully cheer him up. She feels more connected to
her companion, and starts working more enthusiastically (interaction).

The sense of connectedness is described in [26] as “a positive emotional experience which is characterized by a feeling of staying in touch within ongoing social relationships" pp.1.

The research group working on the New Sense of Place project believed that the location-signaling capability of a system holds great potential in the sense of collective presence in a landscape. In [20], the authors showed how shared spatial location and interaction through 'hybrid exhibit' across the digital and physical worlds can create "socially engaging experience" and a sense of "copresence”. The possibility for locating our friends can improve our sense of being a community [2]. The mediaBoard system, presented earlier, also supports a 'community of practice' approach [15] making a group of learners feel more involved in what they are doing together [21]. As outlined in [27], connectedness plays an important role in determining students' well being as well as their readiness of getting involved with others in relation to the work they have to perform and their learning. They also stressed that physical connectedness, i.e. sharing the same physical spaces, does not necessarily imply feeling connected. For instance, when students are visiting a site they are not necessarily "in touch" with the other visitors.

In the MyArtSpace project, the authors proposed a system to support museum visit through mobile phone web-based services. The system, among other functionalities, gave the possibility to pupils to visualize who else has collected the information about an exhibit, so they could find each other and discuss about it face-toface [28]. This solution, however, was not so successful. Students were already engaged in collaboration in small group and they probably did not need further discussions with other peers. A possible solution to this problem might be represented by another system; Szymanski et al. [29] proposed an electronic audio guidebook system to support interaction among companions during museums and cultural heritage sites. Their prototype implements a so called eavesdrop functionality that promoted exploration of the surroundings without hindering interaction with others.

Jones \& Hiltz [30] stressed the importance of Peopleto-People-to-geographical-Place, or P3-Systems that by providing location information can reinforce existing social bonds, and help individuals to meet appropriate people and "turn acquaintances into friends" [30]. CampusMesh represents one of these systems; it is a location aware geotemporal social matching application. Many other examples can be found in [30]. However, there are not so many examples of systems designed for collaborative learning applications. MapTribe, for instance, is a collaborative mobile learning tool that enables group of users to display the map of the city and the position of their friends, supporting social networking but not supporting social matching [5]. Borcea, Gupta, Kalra, Jones, \& Iftode [31] presented the MobiSoC architecture for mobile social computing applications to improve social connectivity, but also support other functionalities, like the People-People Affinity Learning module that computes social affinities based on factors like similar interests, similar background, common friends, or co-location. 


\section{Support Active Participation}

In this subsection, by active participation we mean supporting participation in the life of a community, in particular of the city. Table III presents a possible scenario. In the following we present a number of systems that promote and support active participation.

Cherubini \& Nova [5] suggested that IT, and location awareness applications in particular, may support a shift of attitudes from people that are simply living the city towards a more vibrant citizenry that can master it. In their opinion, people who master the city "have an active attitude towards the community, they are interested in local politics and want to be up to date with all the activities or initiatives around". On the other hand, people who live the city are those that are not "interested in exploring unknown parts of the city, feel not responsible for the public aspect of the city, etc.” pp.1. We share their believe that IT by offering new services that are more social and situated, could fill the gap between a passive citizen to a more active one. Recent research efforts have actually started looking at active participation in the city.

Pleasurable Cities, for instance, was a FutureLab (www.futurelab.org.uk) exploratory study that looked at how the technology owned by young people could be used to encourage them to express their opinions about their local communities. The main objective was "to provide new channels for young people to express their use of space, and to discuss and comment on their expectations and desires for any development or change of those places" [10] pp.2. This was realized by supporting the link between visual real world signs and virtual conversations, both locally via text messages and remotely via web-based message boards, this also gave visibility to their contributions.

A few more projects from FutureLab should be mentioned discussing this specific role of technology. One of these projects is Snapshot that approaches citizenship education through the activity of news photography. It is intended to immerse users in a virtual environment where the social and cultural issues important to today's young people are played out, in order to engage them by asking to take a stand as they investigate and report on the actions they observe [32].

TABLE III.

SCENARIO 3 - ACTIVE PARTICIPATION

The Municipality has recently made available a web service to allow citizens to send in comments and suggestions for improving the town (encouraging exploration and interaction).

The local school is out for a day in the park. Year 1 notices that the access to the park is rather dangerous for the small ones and for disabled. They therefore decide to submit the issue to the

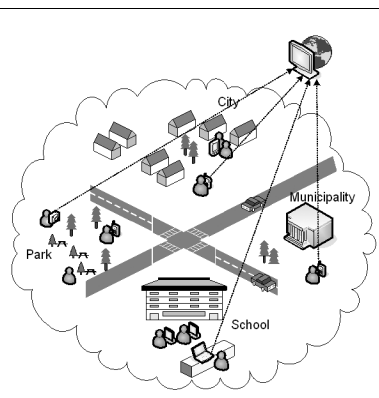
municipality. On the spot, they take some pictures of the area and upload them to the new system with some explanation of the problem (exploration). In the coming days many others leave comments and annotations, confirming that this is actually a problem. Some suggests solutions by attaching sketching to the initial message (serendipity and interaction). A group of architecture students volunteers to design a solution as part of their semester project. Soon this will become a case that the municipality has to address.
TABLE IV.

SCENARIO 4 - VISIBILITY OF LEARNING

The city has made available in a number of public areas, large interactive displays that schools can use to exhibit their work to the community (encouraging serendipity and interaction). Year 1 of the primary school is using the display system to give visibility to their project on local architecture. There are pictures they have taken, a

video, and a brief description of the work. People might interact with the display to look at the different exhibits, navigate in the system, and use their mobiles to leave comments (exploration and interaction). Year 1 is amazed to get so many positive comments to their work. The previous exhibits they organized had been attended only by parents. This system gives schools the possibility to reach a wider audience. A professor teaching architecture at the local university is impressed by their thoughtful analysis and he invites them to visit the exhibit that the university has just set up at the local museum and he offers to be their guide. What a great opportunity! (Serendipity, interaction and further exploration).

MobiMission, instead, is a social game in which players use camera phones with location-based capabilities to create, share and reply to missions created by other. Its main purpose is to engage players in new activities with the physical world and with each other [33].

Active participation can also be realized in other ways. eCell, for instance, promotes active participation through appropriation. Students could claim unused spaces to work with their project and group activities [34]. eCell also support the visibility of learning that is discussed in the next subsection. The Participate projects, instead, promote active participation by making the citizens more aware of what is happening in their environment. The main objective of this project is to promote, through pervasive, online and broadcast media new kinds of massparticipatory events. Within this project a game called "Professor Tanda" has been developed in order to engage the public and make people reflect and be aware of their behavior's environmental impact [35].

\section{Support Visibility of Learning}

With this scenario we want to highlight the possibility to support visibility of learning, see example in Table IV. We believe this is an aspect that should be supported in a urban environment in order to promote the integration of educational initiatives in the activities of the city. Many systems promote and support visibility of learning in a variety of ways.

The eCell is a prototype system for supporting group/project activities in school environments. It consists of a private, inner display and a public, outer display that allowed people passing by the eCell system to learn about others activities [36]. Morken et al. [27] stressed the utility of shared display systems to promote cooperation among students by giving visibility to information, indirectly support coordination and supporting socialization.

Roschelle \& Pea [37] presented the ImageMap system developed by SRI International as "an assessment feedback system for supporting media-rich learning conversations" pp.9. Students receive on their handheld device an image (e.g., graph, map, photo) and a question 
related to it. Each student annotates the image with a response that is sent back to a server. This server receives these responses, aggregates and projects them on a public display, showing also the distribution pattern of different answers, allowing students and teachers to see and discuss about them.

Within this scenario we want to briefly present also other projects that enable interaction and exploration in public places of educational contents that have not necessarily been produced through a learning activity. However, they offer the possibility for learning in a public place, making learning visible to co-located people. La Piazza project represents one example. La Piazza focuses on intergenerational learning in public spaces, e.g. museums, community centers, civic networks, installations in public squares. The focus of this project is both on learning scenarios supported by technology in public social spaces, and the ecological integration of technology interfaces and tools in the physical architecture of those public spaces to support meaningful and playful intergenerational learning activities [38]. One of the La Piazza project case studies is represented by the Space Signpost (www.spacesignpost.com), which is a signpost installed outdoors in Bristol's Millennium Square, that makes space science accessible and visible to everyone.

\section{E. Remarks}

As underlined before, the distinction that we provide here is mainly for analytical purposes. Most of the systems presented here support only one of the roles identified. However, the different roles are often played in an interleaved way in many other systems, as shown in Fig. 2. For example, the eCell [36] system support performance of shared tasks within a group through the use of the inner display; but it also supports active participation and visibility of learning through the outer public display. MyArtSpace [28] is another example of a system supporting both shared tasks performance (in the museums and in the classroom) and social matching, prompting people that have viewed the same exhibit, etc.

\section{CONTEXTUALIZING LEARNING}

From the discussion on technology in the previous section, we see that city-wide applications that support collaborative learning have considerable potential in supporting both formal and informal learning. The full potential can be realized only by acknowledging and supporting the processes of collaborative knowledge creation that take place thanks to the interaction with different actors inside and outside the performance of predefined tasks. Now more than ever there is a need to acknowledge that learning comes from exploration, interaction, and serendipity. City-wide applications have the potential to support these facets of learning in ways that were not possible with traditional desktop applications.

Supporting these facets of learning requires technology that helps learners to take advantage of their context to promote learning. The capability of technology to capture the physical surrounding context until few years ago has been rather limited, being mainly based on direct users' input or on tracking of the status of the situation as represented in the computer. The emergence of mobile and ubiquitous computing has opened new possibilities to build an increased awareness of the surrounding context, for example by tracking the position of users or by sensing environmental data, e.g. the temperature. These possibilities have often led to an increased interest in context-aware computing. Many of the applications in this area are however based on oversimplified accounts of the context where a user is acting [39]. A contextualization of learning to be successful has to take into account that the context is not only given by physical variables, like the location or temperature, but more importantly it has to take into account social aspects. In this perspective we refer to the notion of situated learning introduced by Lave \& Wenger [40] to stress that learning does not happen in a vacuum but is situated in a given context. In this perspective, the acquisition of knowledge should not be fragmented and detached, but tied to a specific context [40]. When situating learning, it is important to account for local and remote social networks, both predefined and emerging, in order to support collaboration within predefined social structure but also to take advantage of serendipitous learning that might be triggered, for example, by people co-location.

In this perspective, we think that the most interesting scenarios for city-wide collaborative learning are the ones that provide a high degree of situatedness with respect to the social network and the place where learning experiences take place (Fig. 3).

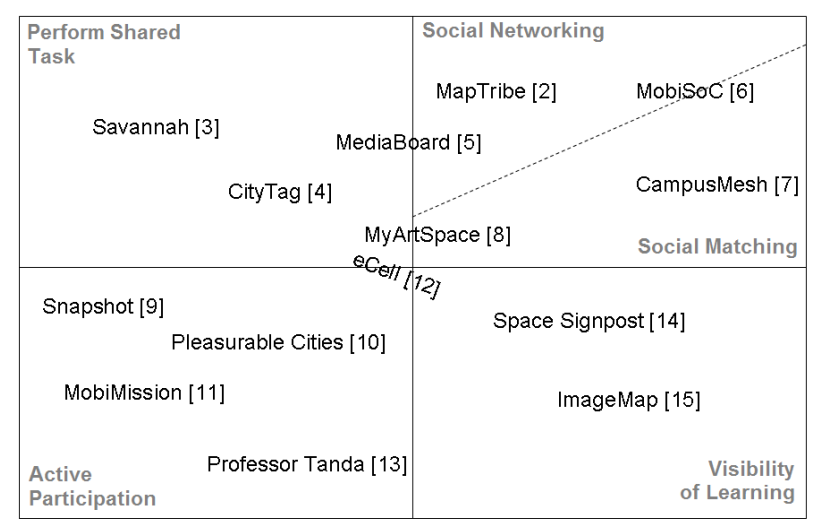

Figure 2. Mapping projects to the identified roles

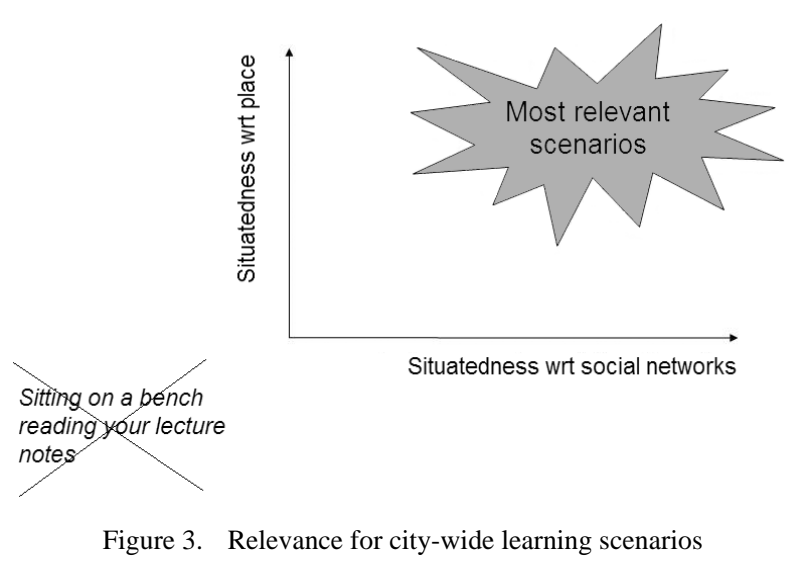

All these scenarios have in common the need to provide representations and management of social networks that users are involved in and of the places that these social networks inhabits. Designing applications that support these scenarios will require to provide: 
- Representations of social networks that are flexible but meaningful, capturing, when needed, the different forms of interleaving of multiple social structures.

- Mechanisms to support participation of users to multiple communities, considering the need of building an overview while keeping focus, and the collaborative co-construction of identity, at the individual and community level, through interaction and participation.

- Mechanisms to share places within communities of users, supporting different levels of abstraction from the geographical positioning and associating them with conventions and rules of conduct.

- Mechanisms to define shared context of learning, taking into account physical and social aspects of the context, and to support the co-construction of shared meaning within different social networks.

We suggest that these requirements should be realized through basic services on top of which more specific applications might be built.

\section{A. Design for a dynamic system}

In general, the context of any learning experience is dynamic, though the level of dynamicity might vary. New people might enter into the social network, different services might be made available, new places might become relevant for a community. As outlined in [41] "the required flexibility can be provided only with a technological infrastructure that supports the rapid development of learning applications and their deployment, promoting grass-root innovation” pp.5. In fact, designing systems that satisfy the varying and dynamically changing needs of communities is challenging. Though a system might function well at a certain point in time, it might not necessarily be able to evolve with the community. It is important therefore to design learning systems that are not monolithic entities, but are rather a dynamic and contextualized composition of services satisfying specific needs. In this perspective one of the challenges ahead is to look at commonalities among different contexts to identify basic services that can then be combined, possibly by end-users, to provide more complex support. This is one of the main challenges addressed in our project. Design and development, in this perspective, have to be strongly coupled with deployment. In fact, learning systems are complex socio-technical systems. Support must be provided to promote this coevolution, in the form, for example, of guidelines, tailoring facilities, end-user development tools.

Learning systems require a high degree of tailoring to the specific needs. The tailoring might go from setting of predefined parameters to the actual development of new services, following the paradigm of end-user development [42]. Given the complexity of defining the context and its evolution, different mechanisms, with different level of automation and user control, should be in place. Also, support should be provided to allow users to easily make available within communities resources that are relevant and share them with others, creating a shared context for learning.

\section{CONCLUSIONS}

In this paper we identified four different roles that technology can play in supporting city-wide collaborative learning, mostly for co-located peers rather than remote ones. For future work we might consider other roles as well, such as real world and virtual world collaboration, etc. However, for each of the roles presented here we provided an illustrative scenario and references to some literature. Based on the identified roles we outlined challenges for technology design. In particular, we suggested that there is a need to support the definition of common services to ease the development of applications for specific learning experiences. In this paper we identified community and place management as two services that are core to city-wide applications.

This paper does not provide any technological or theoretical final solution. Rather, it reflects on the role of technology to start the definition of a design space for the support of city-wide collaborative learning. Identifying the roles of technology and challenges is the first step.

Our future work includes looking in more depth what kind of social networks are relevant in collaborative citywide learning, what kind of support they need for interaction and development, and what kind of shared places are meaningful and need to be provided. Future work will also include the development of specific services and their combination to realize applications fulfilling the needs of specific learning communities. In this process, potential users will play a central role.

\section{ACKNOWLEDGMENT}

We thank the FABULA project participants for constructive discussions and feedbacks. For more information on the project see www.idi.ntnu.no/ divitini/FABULA/.

\section{REFERENCES}

[1] A. Williams and P. Dourish, "Imagining the city: The cultural dimensions of urban computing", Computer, vol. 39, pp. 38-43, 2006. (doi:10.1109/MC.2006.313)

[2] O. Jones, C. Fleuriot, M. Williams and L. Wood, "New geographies of city childhood: Wearable computing devices and children's re-inhabitations of the urban environment," Open Space: People Space, An International Conference on Inclusive Outdoor Environments, 2004.

[3] P. Adamczyk, K. Hamilton, A. Chamberlain, S. Benford, N. Tandavanitj, A. Oldroyd, K. Hartman, K. London, S. Sriskandarajah, E. Kanjo, P. Lanshoff, K. Sezaki, S. i. Konomi, M. A. Niazi, H. F. Ahmad, F. Mirza, A. Ali, G. Roussos, D. Papadogkonas and M. Levene, "Urban computing and mobile devices", IEEE Distributed Systems Online, vol. 8, pp. 1-6, 2007. (doi:10.1109/MDSO.2007.46)

[4] F. Calabrese, K. Kloeckl, C. Ratti, M. Bilandzic, M. Foth, A. Button, H. Klaebe, L. Forlano, S. White, P. Morozov, S. Feiner, F. Girardin, J. Blat, N. Nova, M. P. Pieniazek, R. Tieben, K. van Boerdonk, S. Klooster, E. van den Hoven, J. M. Serrano, J. Serrat, D. Michelis and E. Kabisch, "Urban computing and mobile devices", IEEE Pervasive Computing, vol. 6, pp. 52-57, 2007. (doi:10.1109/MPRV.2007.69)

[5] M. Cherubini and N. Nova, "To live or to master the city: The citizen dilemma: Some reflections on urban spaces fruition and on the possibility of change one's attitude," Imago urbis, 2004.

[6] A. Dieberger, "A city metaphor to support navigation in complex information spaces," Spatial information theory: A theoretical basis for gis, vol. 1329 LNCS Springer Berlin, 1997, pp. 53-67. 
[7] T. Ishida and K. Isbister (Editors), vol. 1765 Lecture notes in computer science, Digital cities: Technologies, experiences, and future perspectives, Springer, 2000.

[8] S. Koizumi and P. v. d. Besselaar (Editors), vol. 3081 Lecture notes in computer science, Digital cities iii: Activities and technologies in digital city kyoto, Springer Berlin / Heidelberg, 2005.

[9] M. Tanabe, P. v. d. Besselaar and T. Ishida (Editors), vol. 2362 Lecture notes in computer science, Digital cities ii: Computational and sociological approaches, Springer Berlin / Heidelberg, 2002.

[10] ] T. Lee, "Pleasurable cities: A discussion paper," FutureLab, Bristol, 2006.

[11] M. Lim and A. Calabrese Barton, "Science learning and a sense of place in a urban middle school", Cultural Studies of Science Education, vol. 1, pp. 107-142, 2006. (doi:10.1007/s11422-0059002-9)

[12] R. H. Nehm, "The effects of a marine and coastal resource education project on urban science teachers' curricula, pedagogical practices, and 'sense of place"', MTS/IEEE Oceans, vol. 1, pp. 119-126, 2005.

[13] S. A. Petersen and A. Kofod-Petersen, "Learning in the city: Context for communities and collaborative learning", Intelligent Environments (IE'06), vol. 2, pp. 3-12, 2006.

[14] G. Valentine, S. L. Holloway and N. Bingham, "Transforming cyberspace: Children's interventions in the new public sphere," Children's geographies: Playing, living, learning S. L. Holloway and G. Valentine (Editors), Routledge, London, 2000, pp. 156173.

[15] E. Wenger, Communities of practice: Learning, meaning, and identity, Cambridge University Press, 1998.

[16] H. Rheingold, Smart mobs - the next social revolution, Perseus Publishing, 2003.

[17] J. Thackara, In the bubble: Designing in a complex world, The MIT Press, 2005.

[18] G. Vavoula and M. Sharples, Challenges in evaluating mobile learning, mLearn2008 Conference, 2008, pp.

[19] N. Pinkwart, H. U. Hoppe, M. Milrad and J. Perez, "Educational scenarios for cooperative use of personal digital assistants", Computer Assisted Learning, vol. 19, pp. 383-391, 2003. (doi:10.1046/j.0266-4909.2003.00039.x)

[20] B. Brown, I. MacColl, M. Chalmers, A. Galani, C. Randell and A. Steed, "Lessons from the lighthouse: Collaboration in a shared mixed reality system", CHI '03, ACM, 2003.

[21] J. Colley and G. Stead, "Mobile learning = collaboration", mLearn 2004, pp. 57-58, 2004.

[22] J. Cook, C. Bradley, D. Holley, C. Smith and R. Haynes, "Introducing blended mlearning solutions for higher education students", mLearn 2006, 2006.

[23] A. Kurti, D. Spikol, M. Milrad, M. Svensson and O. Pettersson, "Exploring how pervasive computing can support situated learning," Proceedings of Pervasive Learning: Design Challenges and Requirements Workshop, 2007.

[24] S. Benford, D. Rowland, M. Flintham, A. Drozd, R. Hull, J. Reid, J. Morrison and K. Facer, "Life on the edge: Supporting collaboration in location-based experiences", $\mathrm{CHI}$ '05: Proceedings of the SIGCHI conference on Human factors in computing systems, pp. 721-730, 2005.

[25] Y. Vogiazou, B. Raijmakers, E. Geelhoed, J. Reid and M. Eisenstadt, "Design for emergence: Experiments with a mixed reality urban playground game", Personal and Ubiquitous Computing, vol. 11, pp. 45-58, 2007. (doi:10.1007/s00779-0060068-5)

[26] J. v. Baren, W. IJsselsteijn, N. Romero, P. Markopoulos and B. d. Ruyter, "Affective benefits in communication: The development and field-testing of a new questionnaire measure", PRESENCE 2003, 2003.

[27] E. M. Morken, M. Divitini and O. K. Haugalokken, "Enriching spaces in practice-based education to support collaboration while mobile: The case of teacher education", Journal of Computer
Assisted Learning, vol. 23, pp. 300-311, 2007. (doi:10.1111/j.13 65-2729.2007.00235.x)

[28] G. Vavoula, J. Meek, M. Sharples, P. Lonsdale and P. Rudman, "A lifecycle approach to evaluating myartspace," 4th Int. Workshop on Wireless, Mobile and Ubiquitous Technologies in Education (WMUTE 2006), 2006, pp. 18-22.

[29] M. H. Szymanski, P. M. Aoki, R. E. Grinter, A. Hurst, J. D Thornton and A. Woodruff, "Sotto voce: Facilitating social learning in a historic house", Computer Supported Cooperative Work, vol. 17, pp. 5-34, 2008. (doi:10.1007/s10606-007-9067-y)

[30] Q. Jones and S. R. Hiltz, "Enhancing urban community enclaves with p3-systems," Metapolis and Urban Life Workshop Proceedings, Ubiquitous Computing Conference, 2005.

[31] C. Borcea, A. Gupta, A. Kalra, Q. Jones and L. Iftode, "The mobisoc middleware for mobile social computing: Challenges, design, and early experiences," Mobilware'08, ICST, 2008.

[32] B. Williamson, "Snapshot: A futurelab prototype context paper," FutureLab, Bristol, 2004.

[33] L. Grant, H. Daanen, S. Benford, A. Hampshire, A. Drozd and C. Greenhalgh, Mobimissions: The game of missions for mobile phones, SIGGRAPH '07: ACM SIGGRAPH 2007 Educators program, ACM Press, 2007.

[34] C. Brodersen and O. S. Iversen, Dressing up for school work: Supporting a collaborative environment with heterogeneous technologies, ECSCW'07, Tenth European Conference on Computer Supported Cooperative, Springer, 2007, pp. 251-270.

[35] M. Wright, A. Chamberlain, C. Greenhalgh, S. Benford, N. Tandavanitj, A. Oldroyd and J. Sutton, "'guess a who, why, where, when?': The visualization of context data to aid the authoring and orchestration of a mobile pervasive game," On the move to meaningful internet systems 2007: Otm 2007 workshops, vol. 4805 LNCS, 2007, pp. 203-210.

[36] C. Brodersen and O. S. Iversen, "Ecell: Spatial it design for group collaboration in school environments", GROUP '05: Proceedings of the 2005 international ACM SIGGROUP conference on Supporting group work, pp. 227-235, 2005.

[37] J. Roschelle and R. Pea, "A walk on the wild side: How wireless handhelds may change cscl", International Journal of Cognition and Technology, vol. 1, pp. 145-168, 2002.

[38] M. Barajas, R. Magli, M. Owen, G. Toccafondi, G. Molari and S. Safin, "La piazza" - convivial spaces for inter-generational learning: Which roles can learning technologies play?" Current Developments in Technology-Assisted Education, vol. 3, pp. 217222, 2006.

[39] S. Greenberg, "Context as a dynamic construct", HumanComputer Interaction, vol. 16, pp. 257-268, 2001. (doi:10.1207/ S15327051HCI16234_09)

[40] J. Lave and E. Wenger, Situated learning : Legitimate peripheral participation, Cambridge University Press, 1991.

[41] E. M. Morken, O. H. Nygård and M. Divitini, "Awareness applications for connecting mobile students," IADIS International Conference Mobile Learning Lisbon, Portugal, 2007, pp. 25-32.

[42] H. Lieberman, F. Paterno, M. Klann and V. Wulf, End-user development, Springer Netherlands, 2006. (doi:10.1007/1-4020$\underline{5386-X)}$

\section{AUTHORS}

I. Canova Calori and M. Divitini are with the Department of Computer and Information Science, Norwegian University of Science and Technology, Trondheim, 7491 Norway (e-mail: [canovaca; divitini]@ idi.ntnu.no).

This work is founded by the NRF-project FABULA (176841/S10).

The article was modified from a presentation at the mLearn2008 Conference, 8th - 10th October 2008 hosted by the University of Wolverhampton. Manuscript received 27 November 2008. Published as submitted by the authors. 